\title{
ITAPECERICA DA SERRA - SP: A VISUALIDADE E A PERCEPÇÃO DO NÚCLEO CENTRAL PELA MEMÓRIA ICONOGRÁFICA E COMPORTAMENTAL
}

Myriam Salomão ${ }^{1}$

\section{Resumo}

O presente trabalho Itapecerica da Serra (SP): a visualidade e a percepção do núcleo central pela memória iconográfica e comportamental é um estudo do espaço central da cidade de Itapecerica da Serra, sua arquitetura, seus usos, vivências e costumes que se perpetuam desde a vila colonial, os grupos sociais que ali vivem ou viveram, suas crenças e ritos e as transformações sofridas pelo núcleo central. Este conteúdo foi analisado por meio de fontes iconográficas (fotografias e mapas). Os dados obtidos na pesquisa histórica e na coleta de material foram comparados e analisados por meio da fenomenologia da percepção, procedimento que evidenciou a influência que as transformações sofridas pelo núcleo central da cidade têm sobre a memória cultural e visual dos habitantes, tornando-a importante dentro do estudo e dando um significado adequado à realidade estudada.

Palavras-chave: Patrimônio cultural, Arquitetura Colonial (SP), Fenomenologia da Percepção.

\begin{abstract}
The present works Itapecerica da Serra (SP): the visuality and the perception of the central nucleus for the memory iconographic and comportamental is a study of the central space of the city of Itapecerica da Serra, its architecture, their uses, existences and habits that are perpetuated from the colonial town, the social groups that there live or they lived, their faiths and rites and the suffered transformations for the central nucleus. This content was analyzed through iconographic sources (pictures and maps). The data obtained in the historical research and in the material collection they was compared and later analyzed through the phenomenology of the perception, procedure that evidenced the influence that the suffered transformations for the central nucleus of the city have about the inhabitants' cultural and visual memory, turning its important inside of the study and making possible to give an appropriate meaning to the studied reality.
\end{abstract}

Keywords: Cultural patrimony, Colonial Architecture (SP), Phenomenology of the Perception.

A percepção do espaço urbano como experiência e fenômeno está na possibilidade de apreensão do cotidiano da cidade para retirar dela mesma os elementos da ação e intervenção sobre ela. Esses elementos não se manifestam como uma certeza, mas como um processo, uma possibilidade e alteram-se de acordo com as características sócioculturais e informativas do morador da cidade e das características físicas, econômicas e de infra-estrutura do espaço urbano. Perceber a cidade é transformá-la em um conjunto de pontos claramente registrados e marcados por um rápido reconhecimento dos espaços. As

\footnotetext{
${ }^{1}$ Mestre em Artes Visuais pelo Instituto de Artes - UNESP, professora de Arte-educação da Faculdade de Educação da Universidade de Santo Amaro - UNISA.
} 
transformações econômicas e sociais também deixam na cidade marcas ou sinais que contam uma história não-verbal, pontilhada de imagens, valores, usos, hábitos e crenças.

No presente trabalho, a imagem (mapas e fotografias) foi a fonte de informação sobre a cidade de Itapecerica da Serra. O início do estudo foi o reconhecimento de Itapecerica da Serra, buscando-se recuperar seu sentido de cidade inicialmente serviu como posto avançado de catequese de índios, visando a formação de um núcleo de defesa do Colégio da Companhia de Jesus de São Paulo de Piratininga. O objetivo não foi somente o de reunir exemplares iconográficos de Itapecerica para realizar uma história ilustrada, mesmo porque muitas das imagens nada têm de ineditismo; pelo contrário, são imagens conhecidas da população: pertencem ao acervo dos Departamentos de Cultura e de Turismo da Secretaria de Planejamento e Meio Ambiente e ao fotógrafo local, Sr. Nelson de Oliveira, sendo que muitas dessas imagens são constantemente utilizadas pela imprensa local para ilustrar matérias diversas nos jornais da região. Outras foram por mim realizadas durante a pesquisa.

A área central foi escolhida por conter exemplares de todo processo evolutivo da ocupação do território da cidade, constituindo a somatória das transformações ocorridas, quer nas edificações e na trama urbana, quer nos usos e vivências desse espaço. A caracterização do local foi indispensável, com o estudo das características físicas, dos usos e transformações urbanas e sociais, ou seja, foi uma análise da realidade tentando desvendar o sistema de produção cultural e vivencial do espaço urbano.

A dinâmica das vivências do espaço urbano ressaltou o aspecto fenomênico do estudo: elas aparecem, desaparecem e ressurgem em diversas épocas e constituem um aspecto próprio do fenômeno cidade: a impermanência do viver urbanamente. Da mesma forma, relatar os usos e hábitos que deram a Itapecerica da Serra sua imagem característica foi resgatar seu sentido de ser no mundo enquanto cidade. Sendo a cidade o mundo artificial criado pelo homem para existir sobre o mundo natural, constatar que ela se transformou, foi constatar que os interesses de seus habitantes se transformaram e que esse mundo artificial ainda não atende à relação que eles mantêm com as coisas, com os outros e consigo mesmo.

De início, a pesquisa contava com as referências teóricas do Urbanismo, com os trabalhos de Guilio Carlo Argan - História da Arte como história da cidade, Camillo Sitte - $A$ construção das cidades segundo seus princípios artísticos, ambos voltados para uma dimensão estética e histórica das cidades, com o acréscimo dos textos de Kevin Lynch - A imagem da cidade que aborda os elementos marcantes que referenciam a locomoção e o uso do cidadão e assim as formas de leitura que o cidadão faz sobre a cidade e de Jason Jacobs - A morte das grandes cidades, que investigam a fisionomia das cidades, do fato dessa fisionomia ter ou não alguma importância e da possibilidade de modificá-la.

Por isso, esse estudo abrange as questões expostas anteriormente, e na medida em que nada se esgota na vida, procurei submeter a cidade a novos olhares, sem esgotá-la (BARBOSA: 2000, p.6), investigando como as transformações e impulsos do núcleo central afetaram na vivência do espaço por seus usuários e habitantes.

Para essa análise, os instrumentais foram mapas e fotografias de diversas épocas que demonstraram como processou a ocupação da colina central, as edificações, o traçado das ruas e, principalmente, o uso desse espaço pelos habitantes. Isto se justifica porque as relações entre o presente e o passado não podem ser desconsideradas na configuração de um objeto ou de um lugar. As imagens da cidade - fotografias e mapas - são representações da cidade, representações estas que abrigam e expressam as coisas em sua 
manifestação apenas provisoriamente e necessariamente, não traduzem o que é o ser para os homens quando realizada, nem quando observada novamente em outro momento. Porém, uma pesquisa da percepção da imagem da cidade como elemento indispensável para a produção da identidade e dos significados urbanos não pode deixar de recorrer a este instrumental.

\section{1 - Formação do núcleo central de Itapecerica da Serra}

A origem de Itapecerica da Serra, divulgada inclusive pela Prefeitura Municipal até a década de 1980, dava a seguinte versão histórica: em julho de 1562, por força de um levante armado, que culminou em ataque ao colégio de Piratininga pelos índios, os padres da Companhia de Jesus viram-se na contingência de fazer instalar uma defesa avançada através da criação de núcleos de índios catequizados em pontos estratégicos para a melhor defesa do planalto. Entre agosto e setembro do mesmo ano, foram instalados os postos avançados de Carapicuíba, Embu, Itapecerica, Guarulhos, São Miguel e outros. Desta forma, Itapecerica da Serra foi um aldeamento indígena fundado pelos padres da Companhia de Jesus, aproximadamente em 3 de setembro de 1562, ou seja, sua origem estaria no século XVI.

Esta afirmação deve-se ao coronel Luiz Tenório de Brito, ex-prefeito do município que na década de 1930, que mesmo não tendo formação acadêmica, realizou as primeiras buscas das fontes históricas, publicando-as em artigos de jornais e periódicos da época. Continuando este trabalho de busca de fontes, Benevides Beraldo, paulista natural de Amparo (SP) e depois morador de Itapecerica, também reforçou estas informações e publicou diversos artigos e crônicas no jornal local a partir de 1956 até 1986, ano de sua morte (CORRÊA: 1999, p.9).

O primeiro historiador que realizou uma produção consistente e apoiada em pesquisa documental sólida foi José Silveira da Motta, que a partir da década de 1970 até o seu falecimento em 1993, recolheu documentos e escreveu estudos sobre a cidade (CORRÊA, p.10). Convém esclarecer também que a referida afirmação do coronel Luiz Tenório foi feita a partir de dedução e não baseada em uma documentação histórica. Atualmente todas as afirmações sobre a história de Itapecerica concordam que o nome da localidade só aparece no século XVII pela primeira vez nos escritos do padre Manoel da Fonseca de 1752, intitulado $A$ vida do venerável padre Belchior de Pontes, que relata a vida do religioso jesuíta natural da região de Itapecerica.

Esta revisão histórica demonstrou como correta a versão de que o aldeamento foi organizado pelos jesuítas no século XVII, possivelmente por volta do ano de 1689, em terras que abriam para o sertão, atrasando em 127 anos o aparecimento da cidade. Porém, poucas fontes restam particularmente do período da administração jesuítica. Não foram encontrados até o momento documentos dando conta da origem de suas terras ou da data oficial da sua fundação, nem de seu fundador. Esta afirmação é reforçada por Pasquale Petrone, professor e historiador da USP, que em seu livro Aldeamentos paulistas (1995) mostra um mapa da capitania de São Vicente entre 1533 e 1597, onde não se encontra referência a Itapecerica nesse momento.

Distante $33 \mathrm{~km}$ da cidade de São Paulo e situada a uma altitude de 920 metros acima do nível do mar, ocupa uma área de $151,8 \mathrm{~km}^{2}$. Tem ao norte o município de Embu, a Leste São Paulo (limitando-se com o bairro de Santo Amaro), a sul Embu-Guaçu e São Lourenço da Serra e a oeste Cotia. Com um clima tropical de altitude e temperatura média de $20^{\circ}$, Itapecerica da Serra está edificada sobre uma colina de formação rochosa, a qual deu origem ao nome da cidade (língua guarani: ita $=$ pedra e pecerica $=$ lisa, escorregadia). Conta a lenda 
que, num lugar conhecido como Caminho do Quara, dois índios passavam e um deles escorregou dizendo ita (pedra) e o outro completou pecerica (lisa).

Segundo a tradição, consta que os primeiros padres jesuítas que para o local se dirigiram, não se conformando com a topografia do terreno onde existia o aldeamento indígena - no alto de uma colina - onde fora construída uma capela, pretenderam mudá-la para um local mais conveniente e construíram uma capela a pouco mais de um quilometro do antigo local, para onde foi transferida a imagem de Nossa Senhora dos Prazeres, padroeira da aldeia. Aconteceu, porém, que a imagem da padroeira, certa manhã, encontrava-se novamente no altar da antiga capela e, para justificar o mistério da mudança, os indígenas informaram aos jesuítas que a santa, não podendo acostumar-se com a nova residência, havia voltado para a velha capela. Assim, os jesuítas construíram uma outra capela com paredes de terra socada (taipa), no lugar denominado Pinhal, pouco mais de um quilômetro da aldeia e situada ao pé da mesma, para onde foi transferida a imagem da padroeira da aldeia.

No decorrer dos séculos XVII e XVIII, quando houve uma relativa estagnação de Itapecerica enquanto prosperavam os núcleos de Moji das Cruzes e Santana do Parnaíba, respectivamente a leste e noroeste do Planalto de Piratininga (CORRÊA, p.77). Até o início do século XIX, a cidade praticamente manteve sua ocupação original. O passado indígena deixou poucos sinais, pois na época da chegada dos imigrantes alemães (1828) custeados pelo governo imperial, muitos índios já havia emigrados do aldeamento, enquanto que os lá estavam eram fisicamente miscigenados e socialmente assimilados.

Itapecerica era apenas um núcleo onde se instalou uma economia rudimentar, constituindo uma espécie de apêndice das propriedades rurais. A grande disponibilidade de terras, a policultura de subsistência nas chácaras, o emprego da mão-de-obra escrava indígena e negra em todo tipo de serviço (lavoura, serviços domésticos, transportes), tudo parecia contribuir para a dispersão econômica e social. O núcleo da colina praticamente não tinha vida urbana, pois quase todas as atividades se continham nos limites das propriedades rurais.

Em torno da igreja paroquial e de um pequeno comércio, com o armazém de secos e molhados e a loja de roupas e tecidos, o núcleo se constituía. A quase totalidade dos moradores era de lavradores que viviam normalmente dispersos na vizinhança, às vezes até muito afastados, que só vinham aos domingos e dias de festa. De população fixa, contava apenas com raros comerciantes e excepcionalmente com algum artífice.

A formação do núcleo urbano de Itapecerica da Serra se deu sobre a estrutura do antigo aldeamento; conservou a implantação do sítio em acrópole e o largo com o qual se defronta a atual igreja, edificada no mesmo local da antiga capela de Nossa Senhora dos Prazeres. Afora a sua localização, não tem nada a ver com a capela construída pelos jesuítas no início do aldeamento. A construção da edificação atual iniciou-se em meados do século XIX, sobre os escombros de uma capela colonial feita em taipa, tendo sido finalizada por volta de 1888. Posteriormente, ela foi reformada diversas vezes (ARROYO: 1971, p.53). Atualmente, três praças principais se destacam no aglomerado urbano: o Largo da Matriz, com a Igreja de Nossa Senhora dos Prazeres, a Câmara Municipal (antiga cadeia pública) e antigas residências transformadas hoje, na sua maioria, em estabelecimentos comerciais; a Praça João Pessoa, onde se concentram bares, estabelecimentos comerciais e bancários e por fim, a Praça 15 de novembro que concentra edifícios de uso do poder público (sede da Prefeitura Municipal, Biblioteca Pública, Secretaria de Planejamento e Meio Ambiente).

As ruas Luiz Gama, Major Teles, Ladeira Capitão Moraes e Avenida 15 de novembro ligam essas três praças e concentram toda a vida comercial da cidade (as lojas, os armazéns, escritórios, lanchonetes), além de possuir algumas residências. 


\section{2 - Transformações do núcleo central}

As sucessivas modificações do espaço natural e do edificado, sempre em função do crescimento da cidade, não podem ser dissociadas das transformações do perfil da população residente na cidade, que por sua vez transforma-se no decorrer do tempo. Até o início do século XIX, a cidade de Itapecerica da Serra praticamente manteve sua ocupação original. Fatores geográficos e sociais explicam a permanência da ocupação original por longo tempo.

Em torno da igreja paroquial e de um pequeno comércio, a venda e a loja, o núcleo se constituía. A quase totalidade dos moradores era de lavradores que viviam normalmente dispersos na vizinhança, às vezes até muito afastados, que só vinham aos domingos e dias de festa. De população fixa, contava apenas com raros comerciantes e excepcionalmente com algum artífice.

A configuração do espaço e do uso da cidade estava diretamente vinculada a este sistema social e econômico de vida. As ruas e praça principal eram ocupadas pelas residências urbanas dos fazendeiros, e as ladeiras de acesso à cidade eram constituídas pelas casas pertencentes às pessoas menos abastadas.

A ocupação do solo era empírica e as ruas deixavam-se modelar pela sinuosidade do terreno, sendo definidas ou delimitadas pelas construções, dispostas segundo o capricho de seus donos.

A vida na zona rural, por sua vez, favorecia o estabelecimento de moradia permanente: um dos problemas da vida urbana era o abastecimento, e soluções satisfatórias somente eram conseguidas nas propriedades rurais, onde, através do trabalho escravo, era desenvolvido o cultivo de alimentos, a criação de aves e porcos, contando com a presença de cursos d'água. Assim, a ocupação do solo se deu de acordo com o tradicional estilo português de conformação de núcleos urbanos: ocupação das áreas ao redor das capelas primitivas.

\section{3 - Vivência do núcleo central}

Para a Fenomenologia da Percepção de Merloy-Ponti (1999), toda experiência visual está inserida num contexto de espaço e tempo, assim como a aparência percebida recebe a influência do que se avizinha nesse espaço e daquilo que já se sabe sobre ele, ou seja, o campo fenomenal é determinado pelas experiências de sensação, associação, projeção das recordações, atenção e juízo.

No presente caso, o espaço central da cidade de Itapecerica da Serra, os usos e vivências da praça central com a igreja matriz, as ruas ao redor e as transformações que verificamos com o passar do tempo, serão os elementos responsáveis pela determinação do campo fenomenal. A área de observação escolhida, núcleo urbano da colina central da cidade de Itapecerica da Serra é delimitado pelas ruas que unem três praças: Praça da Matriz, Praça João Pessoa e Praça 15 de novembro.

A dinâmica das vivências humanas no espaço da cidade é o foco em seu aspecto fenomênico: elas aparecem, desaparecem e/ou reaparecerem em diversas épocas. As vivências selecionadas para o estudo integram o Calendário de Eventos da Prefeitura Municipal de Itapecerica da Serra que mescla atividades religiosas, musicais e culturais. O elemento unificador delas é o espaço central da cidade: são iniciadas ou realizadas na Praça da Igreja Matriz de Nossa Senhora dos Prazeres. 
FESTA DO DIVINO: Festa religiosa estabelecida em Portugal nas primeiras décadas do século XIV pela rainha D. Isabel (!271-1336), casada com o rei D. Diniz de Portugal (1261-1325). Começou com a construção da Igreja do Espírito Santo em Alenquer, de onde a devoção propagou-se rapidamente, tornando-se uma das mais intensas e populares, regulamentada no Código Afonsino. Foi trazida ao Brasil no século XVI. Havia na festa, palanques e coretos armados para o assento do Imperador do Divino, que poderia ser uma criança ou um adulto escolhido para presidi-la e que gozava de direitos majestáticos, libertando presos comuns em certas localidades portuguesas e brasileiras.

É uma festa móvel: quarenta dias depois do domingo da Ressurreição é a quinta-feira da Ascensão do Senhor (Dia da Hora) e dez dias depois é domingo de Pentecostes, dia do Divino Espírito Santo. É precedida por novena e ladainha, com a procissão das bandeiras e a quermesse na praça, assistidas por uma multidão de devotos. Não pode faltar o levantamento do Mastro Votivo com o Império do Divino ricamente ornamentado. O toque das caixas de repique da folia percorrendo as ruas afugenta a doença e traz fartura, principal graça que se pode alcançar com a celebração do Divino (CASCUDO: 2001, p.198-9).

No estado de São Paulo, a devoção ao Divino Espírito Santo constitui-se um dos mais fortes núcleos das devoções populares, sendo uma celebração das mais cheias de pompa e espetacularidade desde os tempos do Brasil Colônia (MACEDO: 2000, p.6).

Esse forte apelo popular da Festa do Divino também está presente em Itapecerica da Serra. Ao que tudo indica, a celebração existia desde os tempos coloniais na cidade. Há um registro fotográfico do ano de 1931 mostrando o vigor que a tradição mantinha e outros dois registros sem data, mas possivelmente de período próximo. O curioso é que em um deles vemos uma criança segurando a coroa, provavelmente o Imperador do Divino.

Após a década de 1980 não há mais registros da ocorrência da festa do Divino em Itapecerica, não sendo possível, no momento precisar o que provocou o desaparecimento da celebração. Há cerca de três anos, a festa do Divino está sendo resgatada através de um projeto do Departamento de Cultura com a comunidade de São Francisco de Itaquaciara, um dos bairros da cidade. A folia percorre o bairro semanas antes da festa, angariando fundos e alimentos para a festa que é realizada na Praça da Matriz. No dia da festa, até chegar na praça, a folia percorre as ruas centras da cidade.

FESTA DE SANTA CRUZ: A devoção à Santa Cruz estimulada pelos jesuítas, popularizou-se depressa entre os índios no início da colonização do Brasil. A cruz plantada pelos missionários nos terreiros das malocas, conduzida processionalmente, saudada pelo canto, autos, pregações e orações diárias, fixava o local das cerimônias religiosas. Foi o primeiro símbolo deixado pelo europeu na terra brasileira (CASCUDO, p.616-7).

No estado de São Paulo, teve início na Aldeia de Carapicuíba por iniciativa do padre Belchior Pontes, durante a catequese dos índios da região, no início do século XVIII. Também é encontrada em Itaquaquecetuba, Cercado Grande e Embu. Durante o período em que a festa se realiza há missa, novena, procissão, leilão, danças, jogos, barraquinhas, levantamento de mastro.

É importante observar em Itapecerica da Serra três aspectos:

$\left.1^{\circ}\right)$ Foi num bairro de Itapecerica que nasceu o padre Belchior Pontes e, conforme dissemos anteriormente, ele esteve nas localidades acima citadas e em sua terra natal no serviço catequético. 
$2^{\circ}$ ) A ladainha de Santa Cruz realizada em Itapecerica da Serra é um evento religioso iniciado há aproximadamente 30 anos por um grupo de senhoras religiosas que procuram resgatar uma tradição cultural de origem no período colonial.

$3^{\circ}$ ) O Cruzeiro da cidade nem sempre foi em frente a igreja matriz: como a igreja é uma edificação de origem jesuítica, com certeza havia uma cruz no terreiro em frente da igreja; nas fotografias pesquisadas, sendo a mais antiga de 1905 indo até por volta do início de 1990, não há cruzeiro na praça da matriz. Ele surge apenas no final dos anos 90 , colocado ao lado do lado da igreja e construído de acrílico azul e branco, com luzes fluorescentes para serem acesas a noite. E o mais interessante: ele foi retirado desse local no mês de maio de 2002, ficando agora em trecho da Avenida 15 de novembro que dá acesso a Itapecerica pela rodovia Régis Bittencourt.

ROMARIAS: Um traço cultural e religioso que se destaca no estado de São Paulo são as romarias: a pé, de bicicleta, a cavalo, de charrete, de motos, de carro, em ônibus fretados ou de carreira. Ocorrem durante todo o ano, apresentando, ciclicamente, grandes picos que chegam a demandar ações especiais dos departamentos de trânsito das cidades santuários.

Em Itapecerica da Serra temos um exemplo bem claro dessas organizações de peregrinos: os Cavaleiros da Fé. Formado de homens de diversas idades, todos cavaleiros e de diversas origens sociais, anualmente se organizam em determinadas ocasiões e partem em marcha para romarias que podem durar diversos dias dependendo da ocasião. Saem sempre da Praça da Matriz, não importa para qual cidade seja a romaria e recebem a benção do padre para que a jornada seja cumprida com tranqüilidade. Há três romarias tradicionais, realizadas todos os anos: romaria à Bom Jesus de Pirapora (pedestres, ciclistas, cavaleiros, charreteiros e veículos motorizados), romaria à São Roque (a cavalo) e romaria à Aparecida do Norte (a cavalo).

CORPUS CHRISTI: A ornamentação dos logradouros em momentos festivos é traço importante de nossa cultura desde os tempos coloniais, de forma especial a procissão de Corpus Christi. Uma das mais solenes procissões católicas em Portugal manteve a tradição no Brasil. Os devotos acompanhavam o pálio sob o qual ia a Santa Hóstia, corpo de Deus, numa custódia de ouro erguida nas mãos da primeira autoridade sacerdotal da localidade (CASCUDO, p.162-3).

É uma festa móvel e o ponto alto é a procissão, acompanhada de cantos litúrgicos. Em Itapecerica as vias públicas são preparadas para a passagem do cortejo religioso por elementos da comunidade que as transformam em tapetes de vivo colorido feito de grãos, contas, sementes, serragem multicor, pétalas de flores e outros materiais. Nos últimos 30 anos a elaboração de tapetes de rua entrou em fase de ascensão, despertando atenção da mídia. Afora o lado expressivo e os excelentes resultados artísticos, destacam-se a extensão desses tapetes, a diversidade de materiais utilizados, mas, sobretudo, o envolvimento de grandes parcelas de todos os segmentos das comunidades.

\section{Referências bibliográficas:}

ARGAN, Giulio Carlo. História da Arte como história da cidade. São Paulo: Martins Fontes, 1992.

ARROYO, Leonardo e DANON, D. Memória e tempo das igrejas de São Paulo. São Paulo: Cia Editora Nacional / Edusp, 1971.

BARBOSA, Alexandre Lourenço (org.). Aparecida: a multiplicidade do olhar. 
Aparecida (SP): s.ed., 2000.

CASCUDO, Luís da Câmara. Dicionário do folclore brasileiro. São Paulo: Global, 2001.

CORRÊA, Dora Shellard. Aldeamento de Itapecerica: de fins do século XVII a 1882. Itapecerica da Serra: Estação Liberdade, 1999.

FONSECA, Pe. Manuel da. A vida do venerável padre Belchior de Pontes. São Paulo: Melhoramentos, s.d.

JACOBS, Jane. Morte e vida de grandes cidades. São Paulo: Martins Fontes, 2001.

LEITE, Serafim. Os jesuítas na Vila de São Paulo. Revista do Arquivo Municipal (São Paulo), n 21, p.3-12, 1936.

LYNCH, Kevin. A imagem da cidade. São Paulo: Martins Fontes, 1999.

MARX, Murillo. Cidade brasileira. São Paulo: Melhoramentos, 1980.

MERLEAU-PONTY, Maurice. Fenomenologia da percepção. São Paulo: Martins Fontes, 1999.

PETRONE, Pasquale. Aldeamentos paulistas. São Paulo: Edusp. 1995.

SITTTE, Camillo. A construção das cidades segundo seus princípios artísticos. São Paulo: Ática, 1992. 